\title{
PRIMARY CILIA EXPRESSION IN BONE MARROW IN RESPONSE TO MECHANICAL STIMULATION IN EXPLANT BIOREACTOR CULTURE
}

\author{
T.R. Coughlin ${ }^{1}$, J. Schiavi², M. Alyssa Varsanik ${ }^{1}$, M. Voisin², E. Birmingham², M.G. Haugh², L.M. McNamara² \\ and G.L. Niebur ${ }^{1 *}$
}

${ }^{1}$ Tissue Mechanics Laboratory, Bioengineering Graduate Program, University of Notre Dame, IN, 46556 USA ${ }^{2}$ Biomedical Engineering, College of Engineering and Informatics, National University of Ireland, Galway, Ireland

\begin{abstract}
Bone marrow contains a multitude of mechanically sensitive cells that may participate in mechanotransduction. Primary cilia are sensory organelles expressed on mesenchymal stem cells (MSCs), osteoblasts, osteocytes, and other cell types that sense fluid flow in monolayer culture. In marrow, cilia could similarly facilitate the sensation of relative motion between adjacent cells or interstitial fluid. The goal of this study was to determine the response of cilia to mechanical stimulation of the marrow. Bioreactors were used to supply trabecular bone explants with low magnitude mechanical stimulation (LMMS) of $0.3 \times g$ at $30 \mathrm{~Hz}$ for $1 \mathrm{~h} / \mathrm{d}, 5 \mathrm{~d} /$ week, inducing shear stresses in the marrow. Four groups were studied: unstimulated (UNSTIM), stimulated (LMMS), and with and without chloral hydrate (UNSTIM $+\mathrm{CH}$ and LMMS $+\mathrm{CH}$, respectively), which was used to disrupt cilia. After 19 days of culture, immunohistochemistry for acetylated $\alpha$-tubulin revealed that more cells expressed cilia in culture compared to in vivo controls. Stimulation decreased the number of cells expressing cilia in untreated explants, but not in $\mathrm{CH}$-treated explants. MSCs represented a greater fraction of marrow cells in the untreated explants than $\mathrm{CH}$-treated explants. MSCs harvested from the stimulated groups were more proliferative than in the unstimulated explants, but this effect was absent in $\mathrm{CH}$ treated explants. In contrast to the marrow, neither LMMS nor $\mathrm{CH}$ treatment affected bone formation as measured by mineralising surface. Computational models indicated that LMMS does not induce bone strain, and the reported effects were thus attributed to shear stress in the marrow. From a clinical perspective, genetic or pharmaceutical alterations of cilia expression may affect marrow health and function.
\end{abstract}

Keywords: Mechanobiology, trabecular bone, primary cilia, bone marrow, MSCs.

*Address for correspondence:

Glen L. Niebur

147 Multidisciplinary Research Building

Notre Dame, IN 46556, USA.

Phone: +1-574-631-3327

Fax: +1-574-631-2174

e-mail: gniebur@nd.edu

\section{Introduction}

Bone marrow is made up of a heterogeneous population of cells of the mesenchymal and haematopoietic lineages. Bone marrow cells are mechanosensitive and, as such, may contribute to the overall mechanobiology of bone (Castillo and Jacobs, 2010; Sims and Walsh, 2012; Soves et al., 2014). For example, isolated marrow cultures form bone in response to cyclic strain (Gurkan et al., 2011). Supporting this concept, inertial loading in the form of lowmagnitude mechanical stimulation (LMMS) induced net bone formation correlated to the mean marrow shear stress in an explant culture model (Birmingham et al., 2015). Complementing these ex vivo studies, in vivo studies have reported bone formation in response to LMMS in trabecular bone (Judex et al., 2007; Rubin et al., 2002; Rubin et al., 2001 ) in the absence of significant matrix strains (Garman et al., 2007). As such, there is growing evidence for a contributing role of bone marrow mechanobiology in bone adaptation.

Many cellular structures have been identified as mechanosensors, including integrins (Batra et al., 2012; Litzenberger et al., 2010), cadherins (Arnsdorf et al., 2009; Marie and Hay, 2013; Xu et al., 2013), and the actin cytoskeleton (Malone et al., 2007). The primary cilium is a cell appendage organelle formed during the quiescent/G1 phase of the cell cycle. It is comprised of nine microtubule doublets that attach to the basal body and is encased in the plasma membrane (Gerdes et al., 2009; Kobayashi and Dynlacht, 2011; Sorokin, 1962; Wheatley et al., 1996). Primary cilia are essential mechanosensors in renal epithelial cells and are also found in MSCs, osteoblasts, and osteocytes (Hoey et al., 2012b; Malone et al., 2007; Praetorius and Spring, 2002). Cilia affect biochemical responses to fluid flow in these cells when cultured in twodimensions (2D) (Hoey et al., 2012b; Malone et al., 2007) by upregulating osteogenic factors (Hoey et al., 2012a). Cells in the marrow express primary cilia in vivo, with a greater concentration near the bone-marrow interface (Coughlin et al., 2015). However, the role of primary cilia in the marrow microenvironment has not been determined.

The means by which cells sense loading and convert it into a biological response is called mechanotransduction. Primary cilia may play a role in osteocyte mechanotransduction, but their role in marrow cell mechanotransduction is unknown. Osteocytes, which are bone cells buried in mineralised bone matrix, are believed to participate in mechanotransduction by sensing deformation of their surrounding lacuno-canalicular 


\section{a}

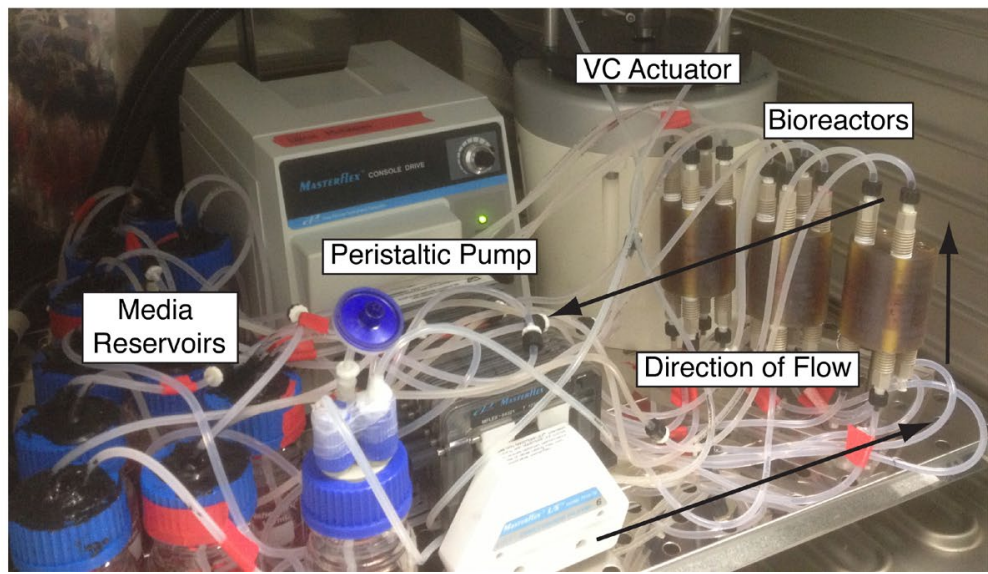

b

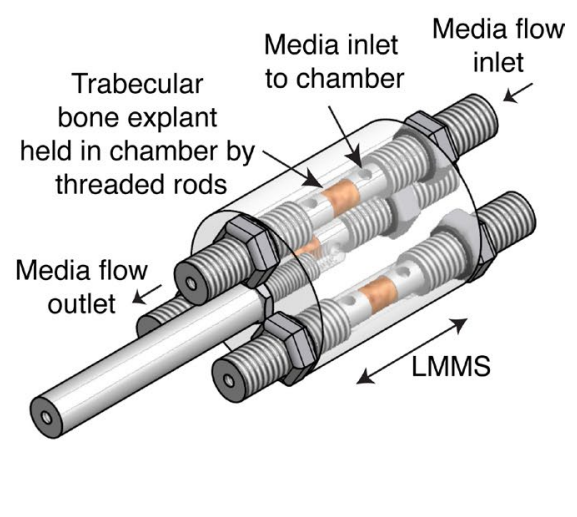

Fig. 1. Bioreactor setup. (a) A voice coil (VC) linear actuator with sub-micron closed loop control applied LMMS to polysulfone culture chambers (bioreactors, detail in b). A peristaltic pump continuously circulated media. Each explant had an individual media reservoir. (b) In the bioreactor chambers, explants were fixed between two threaded rods, which transmitted vibration longitudinally to the explants.

network during loading-induced matrix strain (Darling et al., 2004; Piekarski and Munro, 1977; Verbruggen et al., 2014; Weinbaum et al., 1994). Recent studies indicate that the osteocyte's primary cilium could play a role in sensing this deformation by means of fluid flow (Malone et al., 2007; Nguyen and Jacobs, 2013; Uzbekov et al., 2012), based on experiments with cultured osteoblasts and osteocytes (Hoey et al., 2011; Hoey et al., 2012b; Malone et al., 2007; Uzbekov et al., 2012). In addition, the upregulation of osteogenic genes in MSCs by fluid flow stimulated osteocytes depended on cilia presence in the osteocytes (Hoey et al., 2011). Primary cilia are present in bone marrow resident cells (Coughlin et al., 2015), and have been proposed to act as mechanosensors in human bone marrow derived mesenchymal stem cells (MSCs) (Tummala et al., 2010). Cilia in MSCs significantly change their length in response to hypoxia (Brown et al., 2014), and different media formulations (Bodle et al., 2013).

The goal of this work was to determine whether primary cilia in bone marrow cells play a role in marrow mechanobiology. We hypothesised that mechanical stimulation of the marrow would affect primary cilia expression, and that altering the primary cilium would affect the marrow cell population's response to mechanical stimulation. To test this hypothesis, we studied primary cilia expression and the MSC population after LMMS in an in situ explant culture system (Birmingham et al., 2015). Specifically, we (1) quantified the expression of primary cilia in bone marrow after culture in mechanically stimulated (LMMS) and unstimulated (UNSTIM) conditions; (2) quantified the effect of LMMS on the proliferative potential of MSCs and on bone formation; and (3) determined the effect of knocking down primary cilia on these outcomes.

\section{Materials \& Methods}

\section{Trabecular bone explant: MSC isolation and bioreactor culture}

Trabecular bone explants were obtained from the $\mathrm{C} 2$ vertebrae of immature sheep, 9 to 10 months of age, within $4 \mathrm{~h}$ post mortem. Vertebrae were maintained on ice throughout sample preparation. To isolate explants devoid of cortical bone, vertebral processes and end plates were sawed off to expose the trabecular bone and marrow. Cylindrical explants, $8.1 \mathrm{~mm}$ in diameter, were prepared using a diamond-tip core drill (Starlite Industries, Bryn Mawr, PA, USA) at low drill speeds to minimise heating and damage to the explants. All drilling and sawing was performed with ice cold, sterile phosphate buffered saline (PBS) with $3 \%$ antibiotic/antimycotic $(\mathrm{AB} / \mathrm{AM})$ as a lubricant. The cores were cut to uniform lengths with parallel ends using a low-speed diamond saw (Beuchler Isomet, Lake Bluff, IL, USA).

To isolate marrow cells, the marrow was centrifuged from each explant at 3,500 $\times g$ and plated into T175 flasks. The cells were expanded to passage 3 in MSC growth media (89 \% high glucose Dulbecco's Modified Eagle's Medium (DMEM), $10 \%$ foetal bovine serum (FBS), $1 \%$ antibiotic/antimycotic (AB/AM)).

For bioreactor culture, the isolated explants were placed into bioreactors with continuously circulating MSC growth media (Fig. 1a,b).

\section{Differentiation assays}

Tripotentiality assays were performed to verify that plastic adherent cells were capable of differentiating to the three primary mesenchymal phenotypes. Osteogenic and adipogenic assays were performed as described previously (Freeman et al., 2015) and chondrogenic assays were carried out according to (Pittenger et al., 1999), with slight modifications. Osteogenic assays 


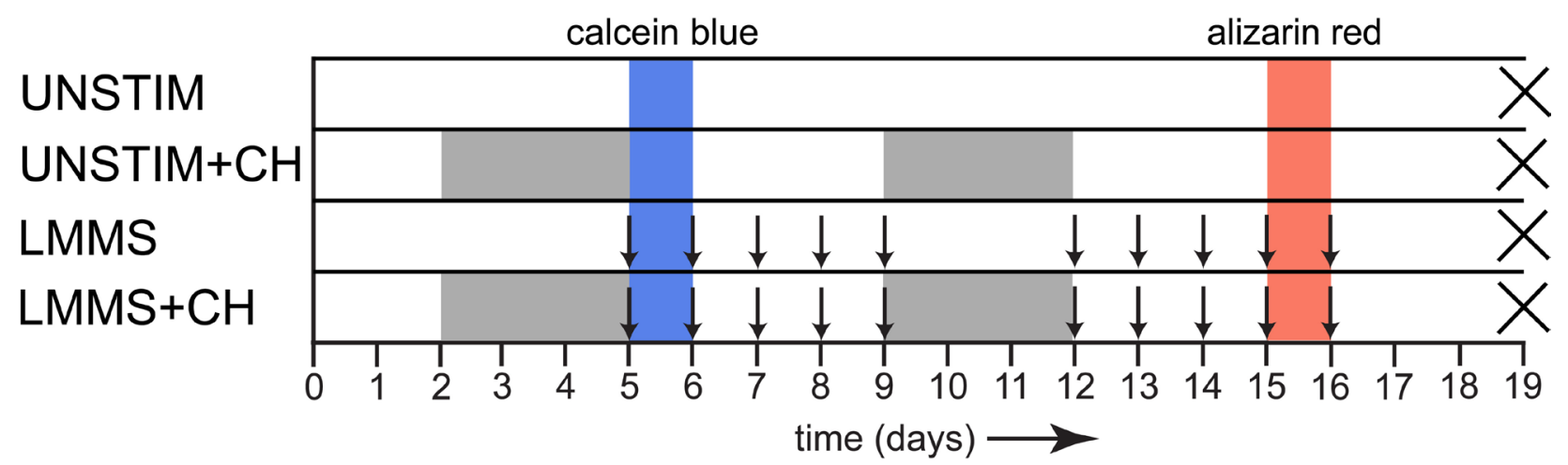

Fig. 2. Experimental design for bioreactor culture. Chloral hydrate was added to the media on day 2 and 9 for $3 \mathrm{~d}$ and media was changed every $24 \mathrm{~h}$ (grey). LMMS was applied on day 5 and day 12 for 5 consecutive days at $30 \mathrm{~Hz}$, $0.3 \times g$ for $1 \mathrm{~h} / \mathrm{d}$ (arrows). Fluorochrome labels were administered overnight on day 5 and day 15 using calcein blue and alizarin red, respectively. On day 19, explants were fixed for histology, IHC, and fluorescent imaging and cells were extracted from explants for CFU-F assays.

were stained for mineralisation with alizarin red, and adipogenic assays were stained for lipids with oil red $\mathrm{O}$. Briefly, chondrogenesis was induced using 250,000 cell pellets with high-glucose DMEM, $2 \mathrm{mM}$ L-glutamine, $1 \% \mathrm{AB}, 100 \mathrm{nM}$ dexamethasone, $50 \mu \mathrm{g} / \mathrm{mL}$ ascorbic acid 2-phosphate, $40 \mu \mathrm{g} / \mathrm{mL}$ L-proline, $1 \%$ of ITS (Sigma), $5.33 \mu \mathrm{g} / \mathrm{mL}$ linoleic acid, $1 \mathrm{mM}$ sodium pyruvate and $10 \mathrm{ng} / \mathrm{mL}$ of transforming growth factor $\beta-3$. Chondrogenic assays were assessed after $21 \mathrm{~d}$ using $0.1 \%$ nuclear fast red to counterstain nuclei and alcian blue at $1 \% \mathrm{pH} 1$ to stain glycosaminoglycans (GAGs), indicative of chondrogenesis.

\section{Effect of chloral hydrate on cilia expression in ovine MSCs and bone marrow}

Chloral hydrate $(\mathrm{CH})$ was used to knockdown primary cilia. The effect of $\mathrm{CH}$ on ovine MSCs was first assessed in monolayer culture. In kidney cells subjected to $68 \mathrm{~h}$ of $\mathrm{CH}$ treatment and then switched to normal medium, appeared normal and remained without cilia for $72 \mathrm{~h}$ (Praetorius and Spring, 2002). At $96 \mathrm{~h}$ in normal media, only short cilia were observed on a fraction of these cells. As such, the knockdown and recovery of cilia by $\mathrm{CH}$ in ovine cells was verified in two experiments.

First, trabecular bone explants were excised from the cervical vertebrae of three sheep, one from each sheep. Isolated marrow cells were plated at a density of 10,000 cells $/ \mathrm{cm}^{2}$ on collagen-coated slides. After $24 \mathrm{~h}$, the media was supplemented with $4 \mathrm{mM} \mathrm{CH}$ for $72 \mathrm{~h}$, which was refreshed every $24 \mathrm{~h}$ (Delaine-Smith et al., 2014; Praetorius and Spring, 2002). Immunocytochemistry (ICC) using anti-acetylated $\alpha$-tubulin (Abcam, Cambridge, MA, USA), a marker of primary cilia (Malone et al., 2007), was performed at $24 \mathrm{~h}$ intervals after $\mathrm{CH}$ treatment was complete to examine the disruption and recovery of the primary cilia over a $96 \mathrm{~h}$ period.

The efficiency of $\mathrm{CH}$ on primary cilia knock down in trabecular bone explant marrow was determined using in situ bioreactor culture of twelve trabecular bone explants. The explants were cultured in two groups, with and without $\mathrm{CH}( \pm \mathrm{CH})$. Explants in the $+\mathrm{CH}$ group were cultured in
MSC growth media for $2 \mathrm{~d}$ before media was supplemented with $4 \mathrm{mM} \mathrm{CH}$ for $72 \mathrm{~h}$, refreshed every $24 \mathrm{~h}$. On day 5, all explants were returned to normal MSC growth media. Three explants in each group were fixed in $10 \%$ neutral buffered formalin on day 7 (48 h after $\mathrm{CH}$ treatment) and the remaining explants were fixed on day $9(96 \mathrm{~h}$ after $\mathrm{CH}$ treatment). Following fixation, explants were dehydrated, paraffin embedded, and prepared for histology and immunohistochemistry (IHC).

\section{Effects of LMMS and cilia knockdown}

The interaction between mechanical stimulation by LMMS and cilia knockdown on the MSC population and bone formation was examined on twelve trabecular bone explants. Four groups of three explants from different animals were studied: unstimulated (UNSTIM), stimulated (LMMS), and unstimulated (UNSTIM+CH) and stimulated (LMMS $+\mathrm{CH}$ ) with $\mathrm{CH}$ treatment. Media in the $+\mathrm{CH}$ groups was supplemented with $4 \mathrm{mM}$ chloral hydrate for $72 \mathrm{~h}$, on days 2 through 5 and on day 9 through 12 to disrupt the primary cilia (Fig. 2). There was no stimulation during $\mathrm{CH}$ treatment.

On days 5 through 9 and 12 through 16, stimulated groups were subjected to LMMS at $0.3 \times g, 30 \mathrm{~Hz}$ vibration for $1 \mathrm{~h} / \mathrm{d}$ in a single loading bout (Fig. 2) according to (Birmingham et al., 2015), where this loading regime caused an anabolic response in trabecular bone explants. LMMS was applied by a feedback controlled voice coil actuator (Bose Enduratec, Edenprarie, MN, USA). Fluorochrome labels, calcein blue and alizarin red, were added to the media overnight on day 5 and day 15 , respectively, to assess mineralising bone surfaces (Fig. 2). All groups were harvested after $19 \mathrm{~d}$ of culture, which was $6 \mathrm{~d}$ after the last $\mathrm{CH}$ treatment in the $+\mathrm{CH}$ groups. Prior to demineralisation, explants were cut in half longitudinally using a low-speed diamond saw. One half of each explant was fixed, demineralised, and prepared for histology and IHC, while the other was trypsinised and centrifuged to remove the marrow. Marrow was removed from the explants by centrifugation at 3,500 $\times g$. After marrow was removed, the remaining trabecular bone was embedded 
for histomorphometry, as described below. Sections for histology, IHC, and histomorphometry were taken least $50 \mu \mathrm{m}$ from the cut surface of the bone.

\section{Immunohistochemistry for cilia expression}

IHC was performed on two $20 \mu \mathrm{m}$ sections of each explant to detect the presence of primary cilia. An anti-acetylated $\alpha$-tubulin (Abcam) primary antibody was used to target the primary cilium, and proteinase K ready-to-use (Dako) was used for antigen retrieval. Samples were immuno-labelled, based on previous protocols (Coughlin et al., 2015). Briefly, anti-acetylated $\alpha$-tubulin (Abcam-24610) at $1 / 20$ dilution and Dylight 488 1/200 (Jackson ImmunoResearch) were used as primary and secondary antibodies, respectively, and 4' (DAPI) was used as a nuclear counterstain.

Sections were prepared on a rotary microtome. The initial slices at the cut surface of the explant discarded to avoid marrow that was damaged or contaminated by the saw. Immuno-labelled image stacks were obtained to a depth of $15 \mu \mathrm{m}$ using an inverted confocal laserscanning microscope (Nikon) at $60 \times$ magnification with an oil immersion objective. Micrographs were obtained at $1024 \times 1024$ pixel definition using a low scan speed and averaging two images. A $488 \mathrm{~nm}$ argon laser was used to excite Dylight 488 and $350 \mathrm{~nm}$ laser to excite DAPI. Three randomly selected marrow areas, were imaged per section - generating 6 image stacks per explant. Primary cilia were identified, based on their proximity to a cell nucleus (DAPI) and having a stained length greater than $1 \mu \mathrm{m}$, following an established methodology (Coughlin et al., 2015). The length was measured in three dimensions using the Pythagorean Theorem, and correcting for the differing in-plane and out-of-plane resolution of the image stacks. The number of ciliated cells was normalised to the total number of cells, which were counted using the automatic nucleus counter plug-in on Image J (NIH). Data were compared to our previously reported data for freshly harvested ovine bone (Coughlin et al., 2015).

\section{CFU-F assay}

Colony forming unit-fibroblast (CFU-F) assays were performed to assess changes in the MSC population due to LMMS and $\mathrm{CH}$ treatment. Explants were trypsinised for $10 \mathrm{~min}$ and centrifuged at 3,500 $\times \mathrm{g}$ in three steps to remove the marrow. Marrow cells were resuspended in warm media and were plated at a density of 100,000 cells/well in six-well plates. Assays were performed in triplicate for UNSTIM and LMMS groups. The number of cells extracted from the $+\mathrm{CH}$ groups was insufficient to perform triplicate wells. In the UNSTIM $+\mathrm{CH}$ group, one explant provided enough cells for triplicate wells while the other two explants provided enough for one and two wells. In the LMMS $+\mathrm{CH}$ group, two explants were done in triplicate, while one provided only enough cells for one well. Averages were taken first within samples and then across samples. The wells were fixed and stained with crystal violet after $5 \mathrm{~d}$. Colonies were counted, and colony size was measured using ImageJ to determine the fraction of cells in the marrow and their proliferative potential (Lindner et al., 2010).

\section{Histomorphometry}

Histomorphometry was performed to determine the effects of marrow stimulation on bone formation. Half of each explant was embedded using Osteo-bed bone embedding-kit (Sigma), and sectioned at $200 \mu \mathrm{m}$ using a diamond wire saw. Two sections per explant were polished to approximately $120 \mu \mathrm{m}$ using 600 grit polishing paper followed by successive grades of abrasives ending with $0.5 \mu \mathrm{m}$ diamond paste. Sections were imaged on a Nikon i90 microscope using epifluorescence with a UV-1A filter to excite calcein blue and a TRITC filter to excite alizarin red. Eight random $0.68 \mathrm{~mm} \times 0.51 \mathrm{~mm}$ images per section were taken at $200 \times$ magnification. UV-1A and TRITC images were overlaid to visualise labelled bone surface. The percentage of mineralising surface (MS/BS) was determined using ImageJ according to (Parfitt et al., 1987). MS/BS was averaged for each explant and then for each group.

\section{Adipocyte area in marrow}

Haematoxylin and eosin (H\&E) stained sections were used to assess the adipocyte content in the explants. From 4 to 24 random $1.39 \mathrm{~mm} \times 1.04 \mathrm{~mm}$ areas of the marrow of each explant were imaged at $100 \times$ magnification. The adipocyte area in the marrow for each explant was quantified using ImageJ and Matlab (Mathworks) by automatically thresholding to segment the adipocytes and the area was calculated by counting pixels.

\section{Computational modelling of the effects of LMMS on bone and marrow}

Computational modelling was used to assess the relative levels of mechanical stimulation in marrow and bone when subjected to LMMS. One explant was imaged by $\mu \mathrm{CT}$ (Scanco $\mu \mathrm{CT}-80$, Brüttisellen, Switzerland) at $20 \mu \mathrm{m}$ resolution. The images were resampled to $35 \mu \mathrm{m}$ resolution, and tetrahedral finite element meshes of the bone and marrow were created. The bone marrow compartment of the explant was assigned a fluid viscosity of $400 \mathrm{mPa} \cdot \mathrm{s}$ and density of $900 \mathrm{~kg} / \mathrm{m}^{3}$ (Coughlin and Niebur, 2012). An elastic modulus of $15 \mathrm{GPa}$ and a density of $2000 \mathrm{~kg} / \mathrm{m}^{3}$ were assigned to the bone tissue. Transient dynamic solutions of the marrow and bone models subjected to $0.3 \times g, 30-\mathrm{Hz}$ cyclic loading applied to the bone-marrow interface for the marrow model, and to the bottom surface of the bone in the bone model were solved in ADINA $^{\circledR}$ (Watertown, MA). At peak acceleration, the $25^{\text {th }}, 50^{\text {th }}$, and $75^{\text {th }}$ percentile fluid shear stresses were assessed in the fluid model and the average shear strain was quantified in the solid model.

\section{Statistical analysis}

Statistics were analysed by JMP software (SAS, NC). Student's $t$-test or ANOVA with Tukey's HSD post hoc test were used to compare groups in each analysis. 

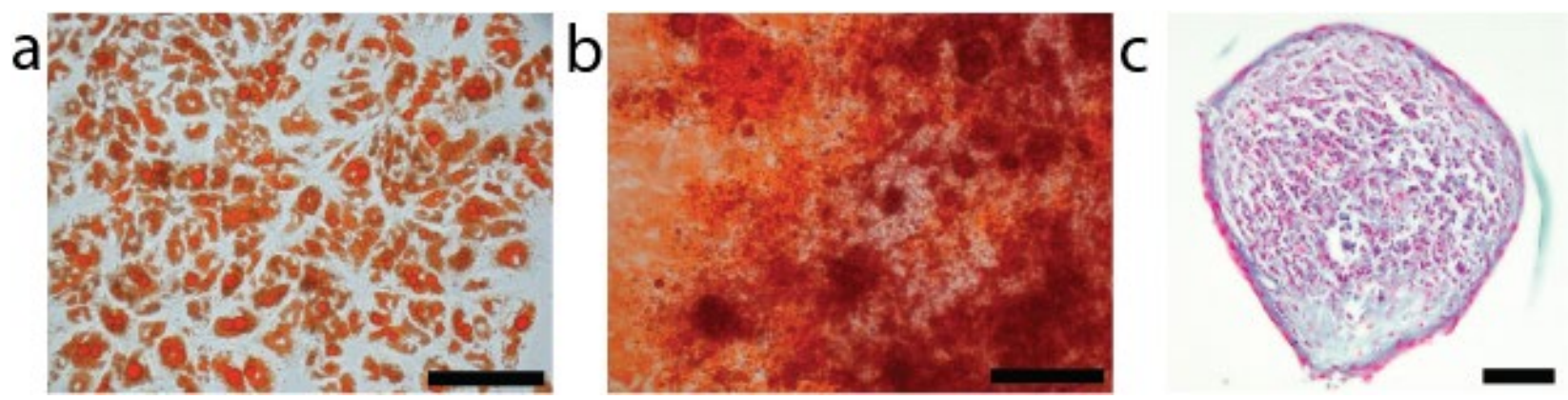

Fig. 3. Ovine bone marrow derived MSCs differentiated along (a) adipogenic (oil red O), (b) osteogenic (alizarin red), and (c) chondrogenic (alcian blue) lines. ( $\mathbf{a}$ and $\mathbf{b}$, scale $=50 \mu \mathrm{m} ; \mathbf{c}$, scale $=100 \mu \mathrm{m}$ ).
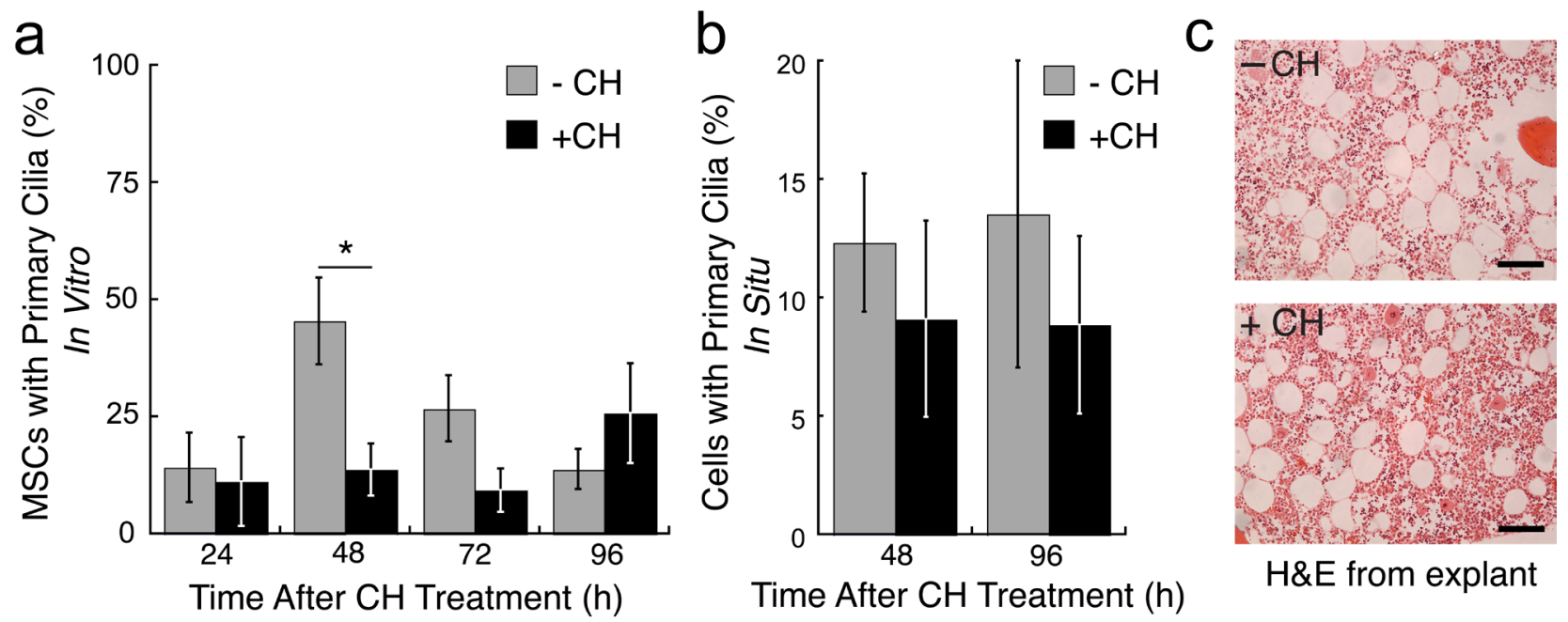

Fig. 4. (a) $\mathrm{CH}$ treatment decreased the number of primary cilia on ovine MSCs on tissue culture plastic at $48 \mathrm{~h}$ after $\mathrm{CH}$ treatment compared to untreated cells (*indicates $p=0.042$ ), Student's $t$-test). (b) In the bioreactor explant culture, there was no difference in cilia expression between $\mathrm{CH}$ treated and untreated groups after 48 and $96 \mathrm{~h}$ of bioreactor culture. Error bars are \pm 1 standard deviation, $n=3$. (c) Haematoxylin and eosin stain showed normal marrow morphology $48 \mathrm{~h}$ after $\mathrm{CH}$ treatment, which in untreated explants is $7 \mathrm{~d}$ of culture (scale $=100 \mu \mathrm{m}$ ).

\section{Results}

\section{Primary cilia presence}

Ovine bone marrow derived MSCs demonstrated their potential to differentiate into mesenchymal lineages, establishing their stem-like nature (Fig. 3). MSCs were immuno-labelled with acetylated $\alpha$-tubulin as they recovered from one bout of $72 \mathrm{~h}$ of $\mathrm{CH}$ treatment (Fig. 4a). Cilia expression varied over time in ovine MSCs cultured in standard MSC growth media $(-\mathrm{CH})$, with a peak of $45.5 \%$ of cells expressing cilia at $48 \mathrm{~h}$. There was no difference in the percentage of MSCs with cilia $24 \mathrm{~h}$ after $\mathrm{CH}$ treatment compared to untreated MSCs cultured for the same number of days (Fig. 4a). However, at $48 \mathrm{~h}$ after $\mathrm{CH}$ treatment there were $32 \%$ fewer MSCs with cilia in treated MSCs $(+\mathrm{CH})$ than untreated MSCs $(-\mathrm{CH})(p=0.042$; Fig. 4 a $)$ There was no difference between $+\mathrm{CH}$ and $-\mathrm{CH}$ groups after $72 \mathrm{~h}(p=0.108)$ and $96 \mathrm{~h}(p=0.351)$.

When explants were treated with one bout of $\mathrm{CH}$ for $72 \mathrm{~h}$, the fraction of cells with cilia in the marrow was not significantly different from untreated explants at $48 \mathrm{~h}$ ( $p=0.334)$ or $96 \mathrm{~h}(p=0.341)$ during recovery from treatment (Fig. 4b). For this short term experiment, the variability was high resulting in statistical power of only 0.12 for $\mathrm{CH}$ treatment, and would have required 16 samples per group to detect a difference. The marrow histology in trabecular explants exhibited no observable physical changes due to $\mathrm{CH}$ treatment (Fig. 4c).

In contrast to the short-term experiment, there was a detectable effect of $\mathrm{CH}$ treatment after $19 \mathrm{~d}$ (Fig. 5a,b). The percentage of marrow cells expressing cilia was higher in all experimental groups compared to uncultured, fresh explants $(p<0.025$, ANOVA; Fig. 5c). After $19 \mathrm{~d}$ in the bioreactor and two bouts of $\mathrm{CH}$ treatment, the fraction of cells with cilia was lower in $+\mathrm{CH}$ groups than in $-\mathrm{CH}$ groups $(p<0.002$; Fig. 5 c). Within the $-\mathrm{CH}$ explants, LMMS further decreased cilia expression $(p<0.05$, Student's $t$-test; Fig. $5 \mathbf{c}$ ), while stimulation had no effect in the $+\mathrm{CH}$ groups.

\section{Colony forming unit-fibroblast assays}

After culture, an average of 1.5 and 0.5 million cells were isolated from the marrow that was extracted from each $-\mathrm{CH}$ and $+\mathrm{CH}$ explant, respectively. Approximately $0.007 \pm 0.005 \%$ of the harvested cells formed colonies in the $-\mathrm{CH}$ groups compared to $0.001 \pm 0.001 \%$ in the 


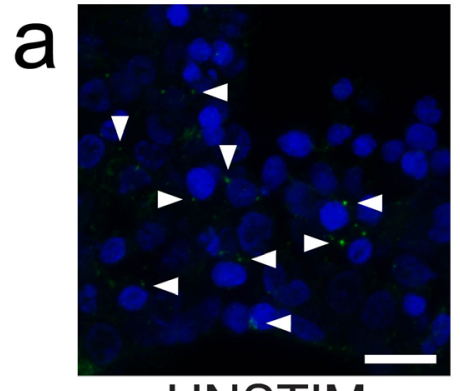

UNSTIM

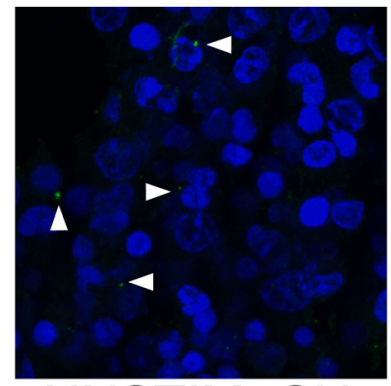

UNSTIM+CH

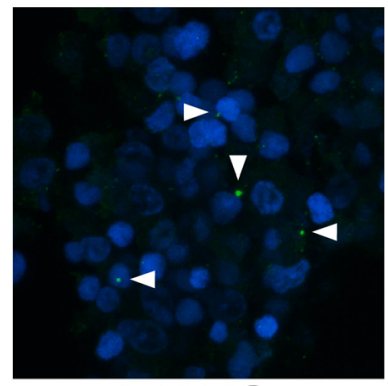

LMMS
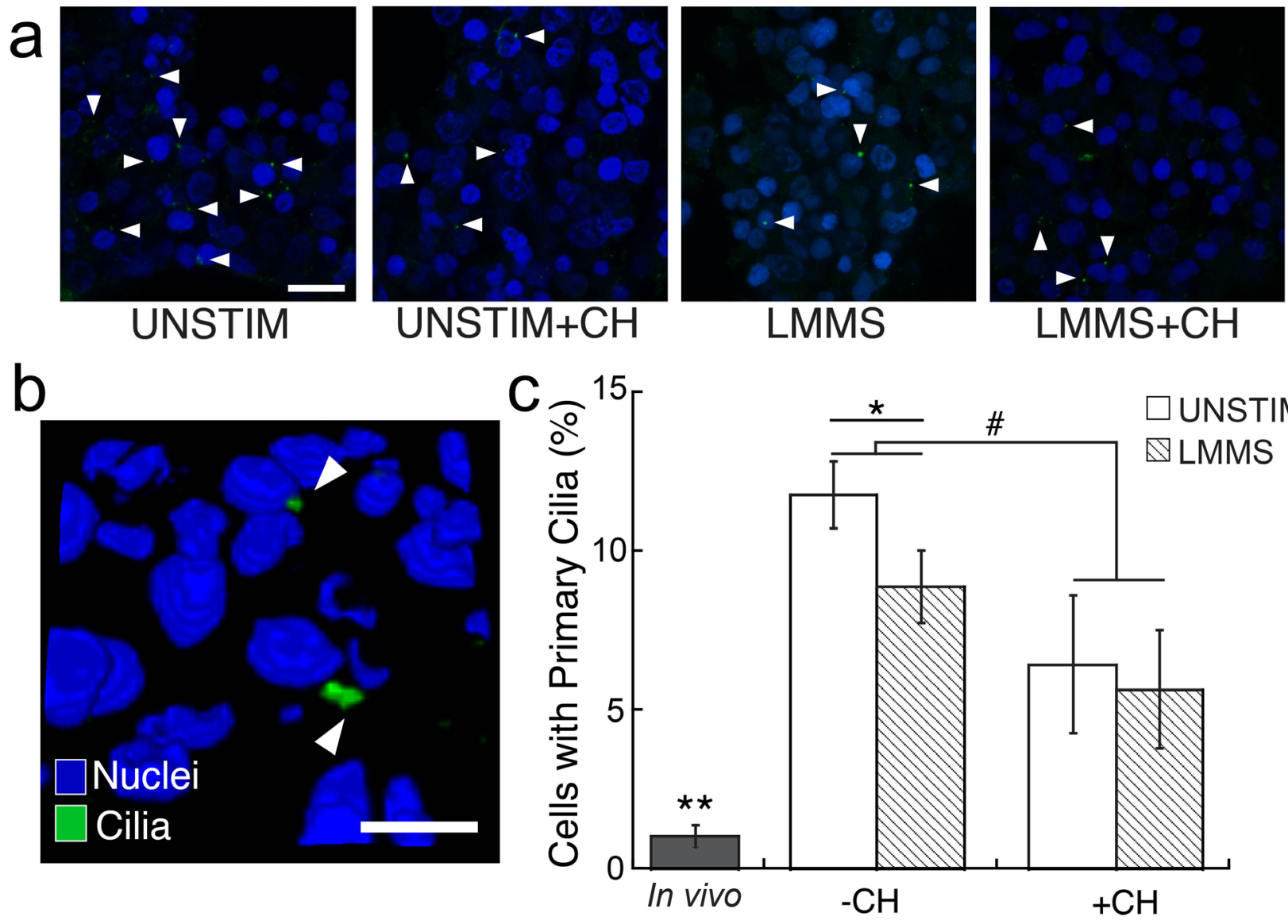

Fig. 5. (a) Representative projections of $15 \mu \mathrm{m}$ sections of marrow immuno-labelled with acetylated $\alpha$-tubulin for primary cilia (green) and DAPI nuclear counterstain (blue) (scale $=10 \mu \mathrm{m})$. (b) Three-dimensional reconstruction of representative cilia in the marrow, where cilia appear in the intercellular space adjacent to nuclei. The top cilium is less than $1 \mu \mathrm{m}$, while the bottom cilium is $2 \mu \mathrm{m}$ in length (bar $=5 \mu \mathrm{m}$ ). (c) The percentage of cells with primary cilia was higher after in situ culture compared to previously reported in vivo data from (Coughlin et al., 2015) (**in vivo differs with all groups, $p<0.025$ ANOVA). Chloral hydrate treatment decreased cilia expression compared to untreated explants (\# $p<0.002$, two-Factor ANOVA). Within the $-\mathrm{CH}$ groups, the LMMS group had fewer cilia expressing cells than UNSTIM (* $p<0.05$, Student's $t$-test). Error bars are \pm 1 standard deviation, $n=3$.

$+\mathrm{CH}$ groups ( $p<0.025$; Fig. 6). LMMS did not affect the number of colonies $(p>0.64)$. However, colonies from explants in the LMMS-CH group were larger compared to the UNSTIM-CH group, indicating a higher proliferative potential ( $p<0.05$; Fig. 6). This effect was not observed in the $+\mathrm{CH}$ groups.

\section{Mineralising bone surfaces and adipocyte content}

$\mathrm{MS} / \mathrm{BS}$ did not depend on stimulation or $\mathrm{CH}$ treatment (Fig. 7). No double labels were detected, so neither MAR nor BFR were measured. The bone marrow maintained a normal morphology in culture, and there was no significant difference in total adipocyte area in the bone marrow (Fig. 8).

\section{Computational modelling of stress in bone and marrow}

The average fluid shear stress in the bone marrow at peak acceleration was $0.09 \mathrm{~Pa}$, while $25 \%$ of the marrow experienced shear stress greater than $0.126 \mathrm{~Pa}$.
When subjected to LMMS at $0.3 \times g$ and $30 \mathrm{~Hz}$, at peak compression the solid bone matrix experienced an average shear stress less than $1 \mathrm{~Pa}$.

\section{Discussion}

This study demonstrates that primary cilia respond to mechanical stimulation in the marrow, and loss of cilia decreases the MSC population. LMMS has been shown to cause mechanostimulatory shear stresses in the marrow space (Coughlin and Niebur, 2012), while causing minimal strain in the bone tissue, as was verified in this study. Bioreactor culture increased the percentage of cells with cilia in the marrow compared to in vivo cilia expression (Coughlin et al., 2015). On the other hand, mechanical stimulation decreased the fraction of cilia expressing cells in the marrow of bioreactor cultured explants, suggesting that cilia expression may be a response to decreased mechanical stimulation. In contrast, when cilia were 


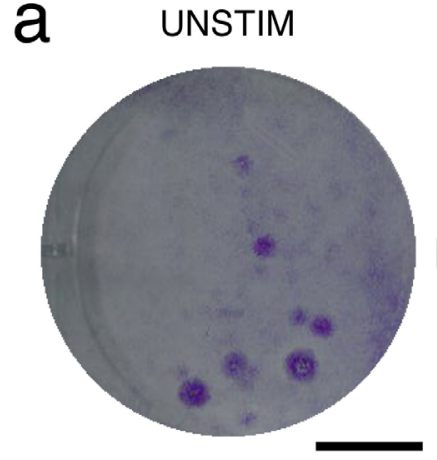

b

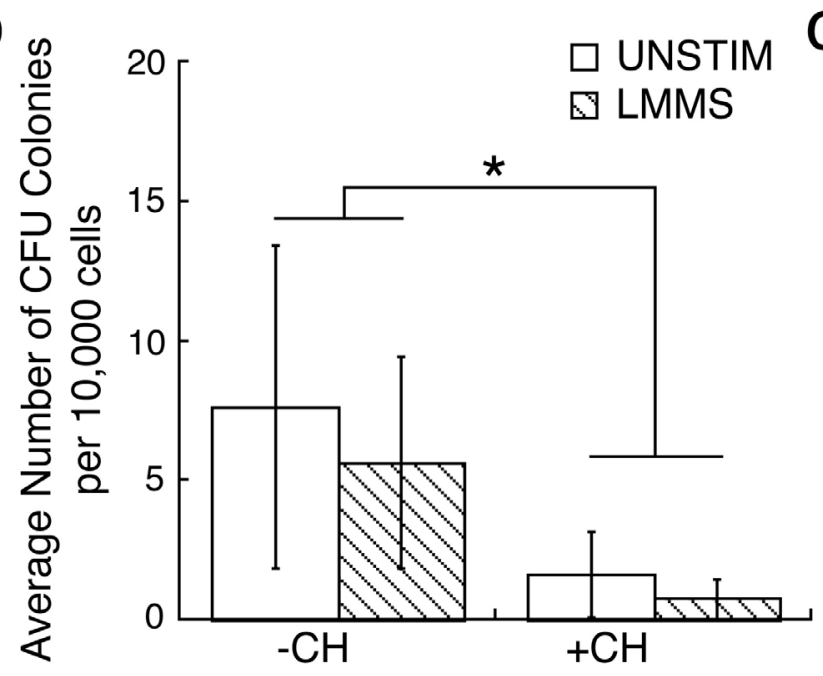

LMMS

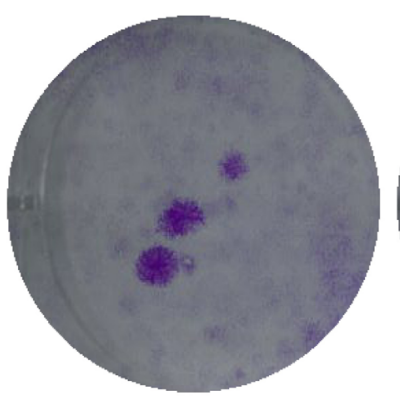

$\mathrm{C}$
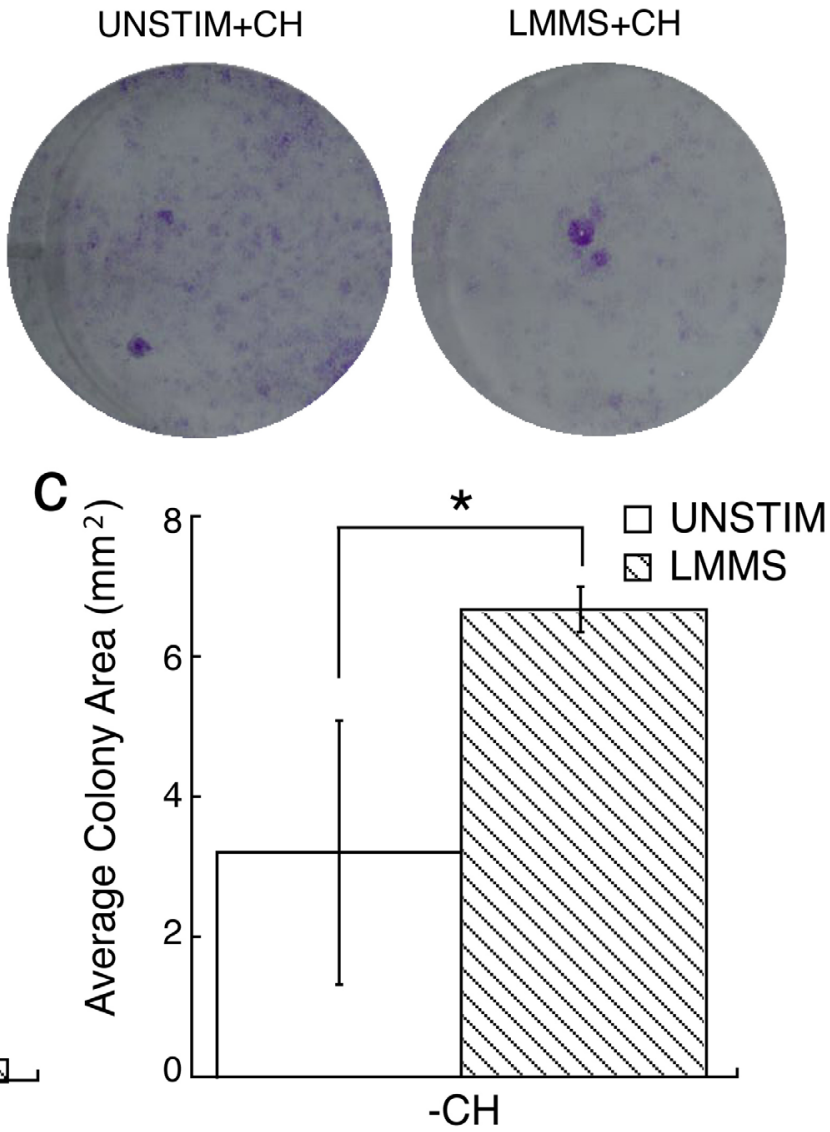

Fig. 6. (a) Representative wells of CFU-F colonies stained with crystal violet $(10,000$ marrow cells were initially plated, scale $=10 \mathrm{~mm})$. (b) Chloral hydrate treatment decreased the number of MSCs $(p<0.05$, two-Factor ANOVA), but LMMS had no effect. (c) The average colony area was higher in the LMMS-CH group when compared to the UNSTIM-CH group $(p<0.05$, Student's $t$-test). There was an insufficient number of colonies to compare the colony size in $+\mathrm{CH}$ groups.
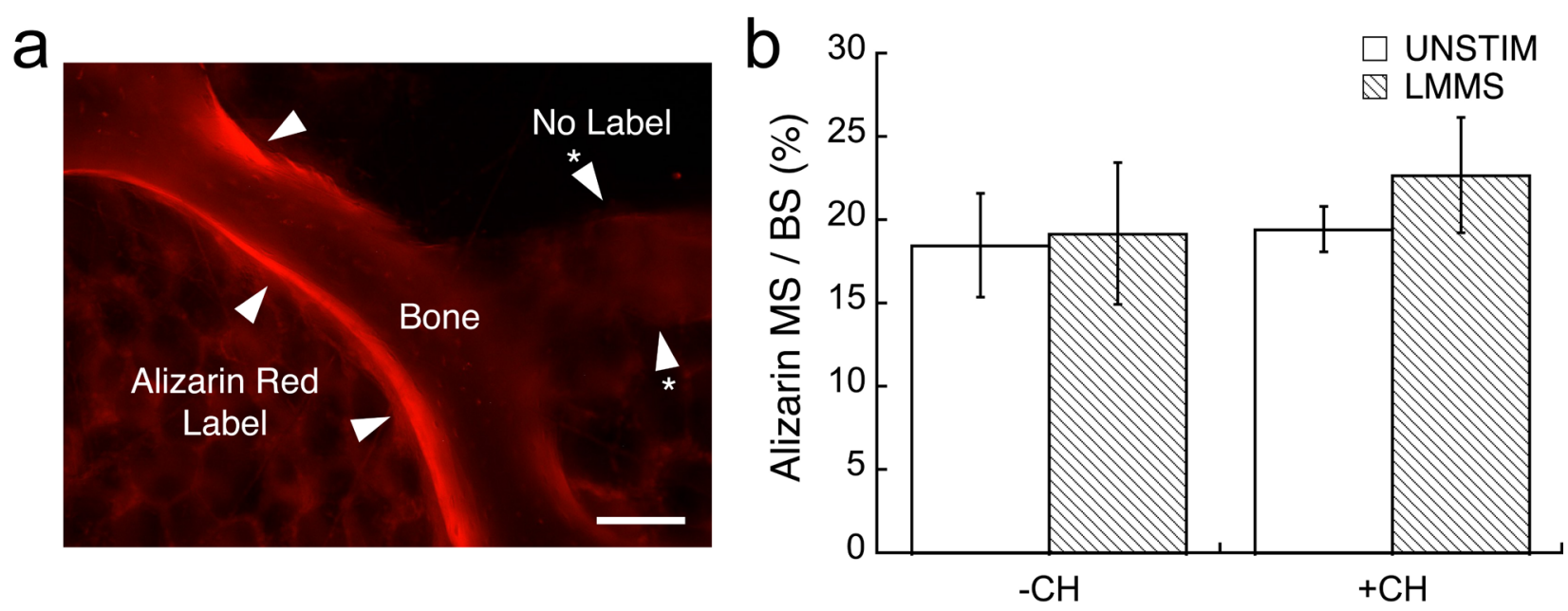

Fig. 7. (a) Mineralising bone on the trabecular bone surface, indicated by the incorporation of alizarin red in the bone (arrowheads). Non-mineralising surfaces were also observed (arrowhead with asterisk) (scale $=100 \mu \mathrm{m})$. (b) Mineralising bone surface was not statistically different between groups (ANOVA).

disrupted by $\mathrm{CH}$, mechanical stimulation did not further affect their expression, possibly because $\mathrm{CH}$ disruption of microtubule formation prevented the cells from altering the cilia. Mechanical stimulation also increased the MSC proliferation potential in the absence of $\mathrm{CH}$, as indicated by the colony size in the CFU-F assays. In contrast, $\mathrm{CH}$ decreased the MSC population in the explant marrow compared to untreated explants after $19 \mathrm{~d}$ of culture. As such, cilia expression is important for maintenance of the MSC population and is related to mechanosensing. Taken together, mechanical stimulation of bone marrow cells decreased cilia expression, a purported mechanosensitive 
a

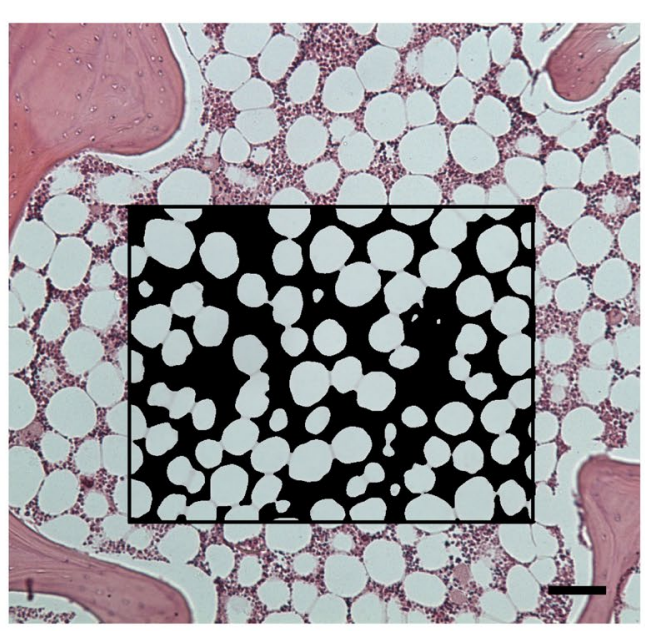

$\mathrm{b}$

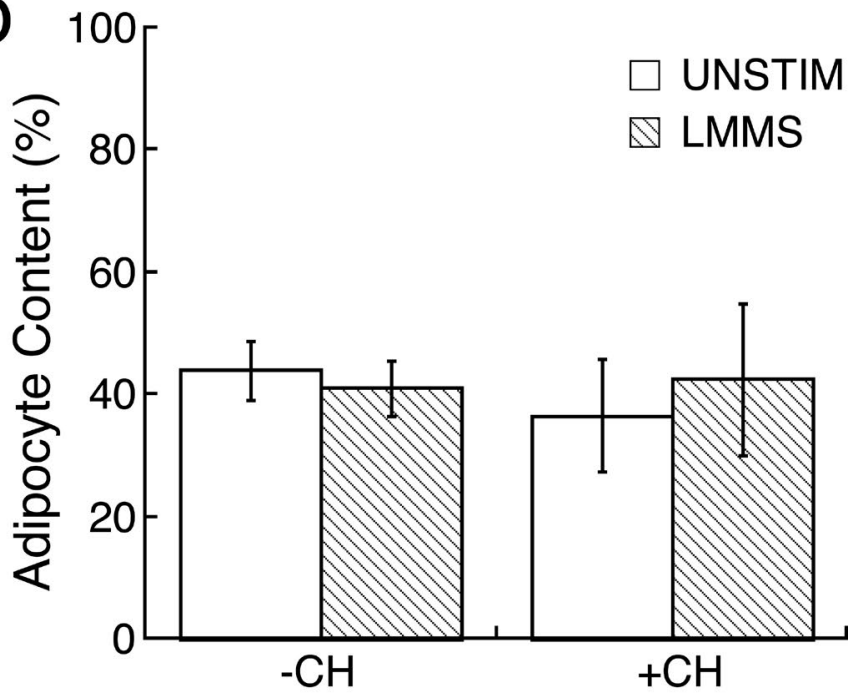

Fig. 8. (a) Haematoxylin and eosin stain of explant marrow and bone (scale $=100 \mu \mathrm{m})$. There were no observable physical differences in the marrow between groups. The adipocyte area was quantified by thresholding using Matlab image processing toolbox (inset, black and white) (Mathworks, Natick, MA). (b) The measured adipocyte area in the explants did not differ between groups (ANOVA).

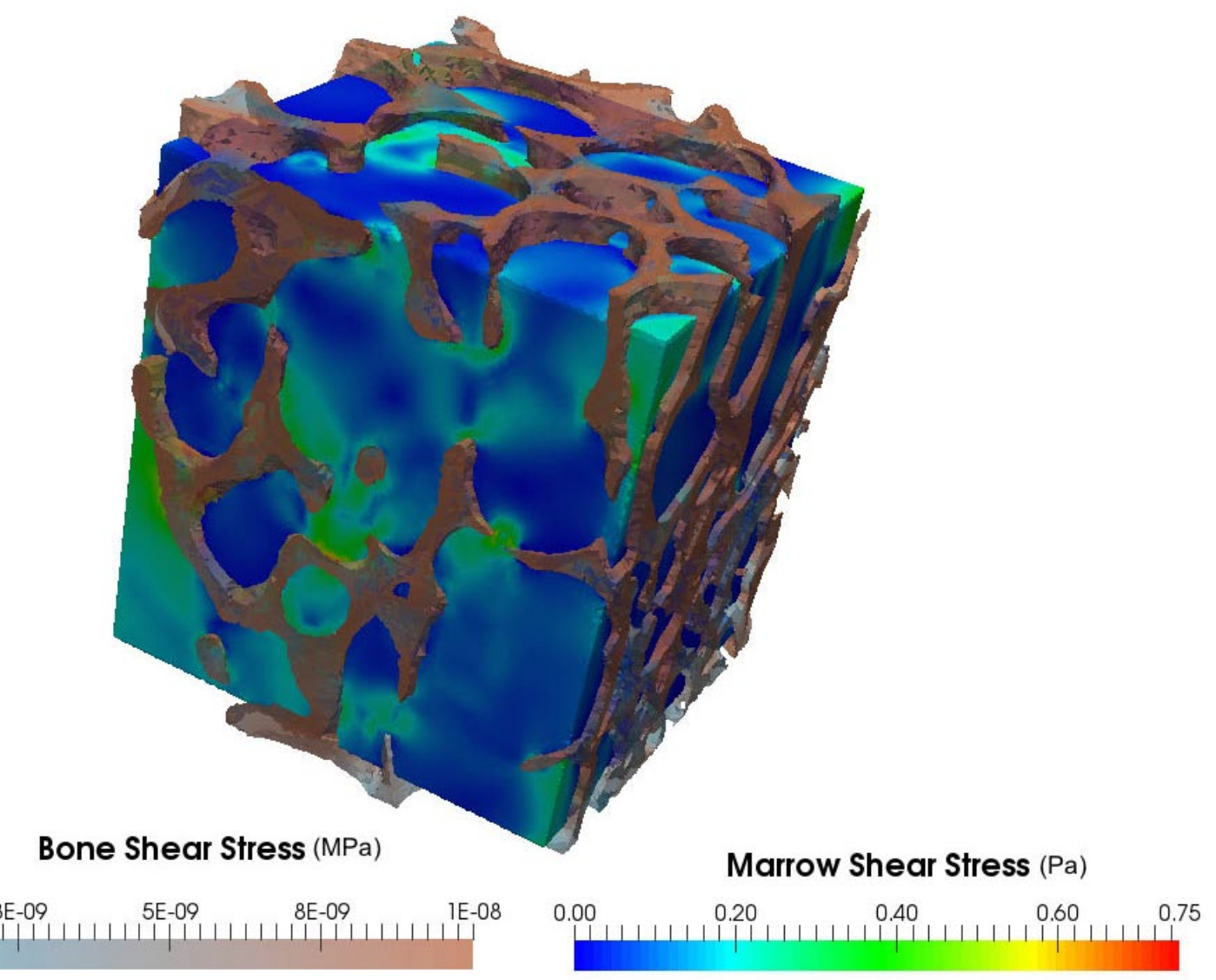

Fig. 9. Fluid shear stresses in the marrow and shear stresses in the trabecular bone at peak acceleration during LMMS at $0.3 \times g$ and $30 \mathrm{~Hz}$. Approximately $10 \%$ of the marrow was subjected to shear stress greater than $0.2 \mathrm{~Pa}$ at the peak, while the solid matrix experienced almost no deformation.

organelle. As such, mechanobiology may play a role in normal marrow function both through cilia and additional non-cilia mediated mechanisms.

The use of in situ bioreactor culture was a novel approach to study the mechanobiology of the marrow.
In situ culture preserves the heterogeneity of the bone marrow compartment, which enables signalling between multiple cell types. Moreover, the explant model provides a mechanism for applying mechanical stimulation that causes shear stresses in the marrow without causing compression 
of the bone matrix, which is believed to be essential for mechanotransduction by osteocytes (Knothe Tate, 2003). Shear stresses in the marrow would be transmitted via both cell-cell and cell-matrix interactions. In contrast, in vitro stretching and fluid flow models rely primarily on cell attachment to the substrate by integrins and low viscosity fluid shear stress on the cell surface. Understanding the differences between the behaviours of cells in 2D vs. threedimensional (3D) culture is essential to translating in vitro results to in vivo situations.

There are several limitations that must be considered with regard to this study. $\mathrm{CH}$ functions to knockdown cilia by disrupting microtubules. Although it has previously been used to study cilia mediated mechanobiology (Delaine-Smith et al., 2014; Malone et al., 2007), CH also affects proliferation (Lee et al., 1987) and may thereby have an effect on cell division in the marrow. However, intracellular microtubules in kidney cells subjected to $68 \mathrm{~h}$ of $\mathrm{CH}$ treatment appeared indistinguishable from control cells after being switched to regular media for $24 \mathrm{~h}$ (Praetorius and Spring, 2002). In addition, $\mathrm{CH}$ is not specific to MSCs and osteoblasts, but affects many types of cells in the heterogeneous marrow cell population. Therefore, further study is needed to isolate and ascribe the results to individual cell populations. A more specific knockout of cilia is possible using polaris siRNA, which disrupts cilia without affecting microtubules. This was not deemed feasible for the current study due to the challenges of ensuring effective transfection within 3D explants, nor would it be population specific. Tissue specific gene knockout in mice may provide a tissue source for more refined studies.

The decreased cilia expression in the marrow population in the LMMS compared to UNSTIM explants is consistent with results in an osteoblast cell line and in tendon. Similar to our results, there were fewer cilia in MLO-A5 mature osteoblasts after flow in in vitro 2D culture (DelaineSmith et al., 2014). In tendon, tenocytes increased the length of their cilia during static culture and retracted the cilia in response to cyclic mechanical stretch of the tendon (Gardner et al., 2011). The altered cilia expression may demonstrate a role for cilia as mechanosensors or a component of a mechanosensitive pathway in situ. Interestingly, the explants treated with $\mathrm{CH}$ did not exhibit changes in cilia expression due to mechanical stimulation, consistent with abrogated function of the remaining cilia (Praetorius and Spring, 2002).

In contrast to previous studies, the MSCs in 2D culture did not uniformly express cilia in our experiments. Previous experiments demonstrate that $90 \%$ of human bone marrow derived MSCs expressed cilia in 2D culture (Tummala et al., 2010). Similarly, in MC3T3-E1s, an osteoblast precursor cell line, and MLO-Y4s, an osteocyte cell line, approximately $61 \%$ and $62 \%$ of cells expressed cilia, respectively (Malone et al., 2007). MLO-A5s, a mature osteoblast cell line, expressed cilia on $67 \%$ and $66 \%$ of cells at two time points $24 \mathrm{~h}$ apart (Delaine-Smith et al., 2014). In our experiment, we used primary cells cultured in growth media with foetal bovine serum, rather than serum starving the cells to impose quiescence and cell cycle synchronisation as is commonly done to promote uniform cilia expression (Schneider et al., 2005; Young et al., 2012). As such, the lower level of cilia expression observed here may reflect that the MSCs were progressing through the cell cycle at different rates, causing peaks in cilia expression at different times as cilia are expressed during the quiescent stage of the cell cycle (Kobayashi and Dynlacht, 2011). This may explain the higher number of cells with cilia at $96 \mathrm{~h}$ after cilia disruption. Because serum is necessary to maintain the cell populations in the explant culture system, we sought to verify the effects of $\mathrm{CH}$ using the same media formulations. The lower baseline cilia expression, rather than the effectiveness of the $\mathrm{CH}$ treatment, likely explains the similarities between the untreated and treated cells. In contrast, for MLO-A 5s treated with $\mathrm{CH}$ for $72 \mathrm{~h}$, the percentage of cells with cilia was reduced by $64 \%$ and $49 \%$ at 24 and $48 \mathrm{~h}$, respectively, during recovery (Delaine-Smith et al., 2014).

In our preliminary experiment to test the efficacy of $\mathrm{CH}$ on primary cilia disruption in trabecular bone explants, we did not detect an effect of $\mathrm{CH}$ on cilia expression. However, after $19 \mathrm{~d}$ of explant culture with two bouts of $\mathrm{CH}$ treatment, the fraction of cells with cilia was lower in treated $v s$. untreated explants. As such, a single $72 \mathrm{~h}$ bout of $\mathrm{CH}$ may not be sufficient for measurable knockdown of the cilia in these cells. Overall, multiple treatment bouts were necessary to deliver a sufficient dose to reduce the number of primary cilia in the marrow cell population in this experiment.

The proportion of cells expressing primary cilia in the bone marrow of cultured explants was higher than in vivo explants reported in Coughlin et al. (2015) $(p<0.01)$, indicating that cells change their expression of cilia in response to the culture environment (Besschetnova et al., 2010; Bodle et al., 2013). This increase is likely a response to changes in the biochemical environment. Cilia in MSCs change their length in response to changes in hypoxia (Brown et al., 2014), different media formulations (Bodle et al., 2013), and in mammalian epithelial and mesenchymal cells cilia modulate their length in inverse proportion to intracellular calcium levels (Besschetnova et al., 2010).

The decreased MSC population following $\mathrm{CH}$ treatment, compared to untreated explants, may be related to cell attachment. In an in vitro study, loss of cilia by siRNA prevented cells from adhering to tissue culture plastic (Tummala et al., 2010). As such, loss of cilia may have prevented colonies from forming in the treated $(+\mathrm{CH})$ groups, rather than reflecting a true loss in the number of progenitors.

The increased MSC proliferation potential in the LMMS compared to the UNSTIM groups complements the increased MSC population following LMMS in vivo. Mice fed a high fat diet and subjected to six weeks of whole-body vibration showed a $46 \%$ increase in the number of MSCs in marrow from the tibia and femur compared to unstimulated controls (Luu et al., 2009). However, the number of MSCs in the LMMS explants was not higher than the UNSTIM explants, despite their higher proliferation potential. Similar in vivo studies found that adipocyte content is affected by LMMS. In a whole body vibration study, fat volume in the torso of mice subjected to LMMS for 12 weeks was $27 \%$ less than control mice, although changes 
in marrow fat content were not reported (Rubin et al., 2007). Indeed, bone marrow adiposity does not correlate with total body fat (Justesen et al., 2001). Taken together, the marrow MSC and adipocyte populations may require longer culture times to be affected by LMMS, and may involve systemic activity such as changes in hormone levels that are not recapitulated in explant culture.

LMMS did not affect the mineralising surface in the explants nor were there double labels present, while other studies have shown an increase in bone formation in explant culture (Birmingham et al., 2015; David et al., 2008; Vivanco et al., 2013). Incorporating osteogenic factors, ascorbic acid 2-phosphate and $\beta$-glycerophosphate, into the media, Birmingham et al. observed bone formation in the same bioreactor culture system (Birmingham et al., 2015). Similar to our results, there was no change in MS/ BS after osteoblast- and osteocyte-specific cilia knockout compared to wild-type animals (Temiyasathit et al., 2012). However, in vitro $\mathrm{CH}$ mediated cilia disruption in osteoblasts decreased calcium deposition by osteoblasts in response to flow (Delaine-Smith et al., 2014).

Primary cilia play an important role in development and maintaining homeostasis (Novarino et al., 2011). Alterations in cilia can lead to ciliopathies that affect numerous tissues including bone, kidney, brain, retina and liver. (Huber and Cormier-Daire, 2012). The presence of cilia in bone marrow and their modulation after mechanical stimulation indicates that the mechanical signal from LMMS is sensed in the marrow, and, like tenocytes, the cells respond by retracting their cilia. Further studies are warranted to identify the function of primary cilia in bone marrow, which may lead to new targets for therapeutics.

The role of primary cilia in a native multicellular environment was investigated here for the first time. Using an explant bioreactor culture system, the bone marrow compartment was stimulated without associated bone deformation. Primary cilia expression increased in response to the culture conditions, but was reduced after mechanical stimulation. Further experiments that delineate whether this result reflects the importance of the cilia as a mechanosensory organelle, or if it is a consequence of pathways activated by other mechanosensors in the cell are needed. The fact that loss of cilia eliminated the effect of LMMS on the proliferative potential of the MSCs is consistent with the former interpretation.

\section{Acknowledgements}

This research was supported by grants from Science Foundation Ireland 07/EN/E015B Travel Fellowship TRC, ERC Grant no. 258992 (BONEMECHBIO) LMMcN. and MV, and U.S. National Science Foundation CMMI-110207 and 1435467 TRC and GLN.

\section{Conflict of interest statement}

The authors have no potential conflicts of interest.

\section{References}

Arnsdorf EJ, Tummala P, Jacobs CR (2009) Noncanonical Wnt signaling and $\mathrm{N}$-cadherin related betacatenin signaling play a role in mechanically induced osteogenic cell fate. PLoS One 4:e5388.

Batra N, Burra S, Siller-Jackson AJ, Gu S, Xia X, Weber GF, DeSimone D, Bonewald LF, Lafer EM, Sprague E, Schwartz MA, Jiang JX (2012) Mechanical stress-activated integrin alpha5beta1 induces opening of connexin 43 hemichannels. Proc Natl Acad Sci USA 109: 3359-3364.

Besschetnova TY, Kolpakova-Hart E, Guan Y, Zhou J, Olsen BR, Shah JV (2010) Identification of signaling pathways regulating primary cilium length and flowmediated adaptation. Curr Biol 20: 182-187.

Birmingham E, Kreipke TC, Dolan EB, Coughlin TR, Owens P, McNamara LM, Niebur GL, McHugh PE (2015) Mechanical stimulation of bone marrow in situ induces bone formation in trabecular explants. Ann Biomed Eng 43: 1036-1050.

Bodle JC, Rubenstein CD, Phillips ME, Bernacki SH, Qi J, Banes AJ, Loboa EG (2013) Primary cilia: the chemical antenna regulating human adipose-derived stem cell osteogenesis. PLoS One 8: e62554.

Brown JA, Santra T, Owens P, Morrison AM, Barry F (2014) Primary cilium-associated genes mediate bone marrow stromal cell response to hypoxia. Stem Cell Res 13: 284-299.

Castillo AB, Jacobs CR (2010) Mesenchymal stem cell mechanobiology. Curr Osteoporos Rep 8: 98-104.

Coughlin TR, Niebur GL (2012) Fluid shear stress in trabecular bone marrow due to low-magnitude highfrequency vibration. J Biomech 45: 2222-2229.

Coughlin TR, Voisin M, Schaffler MB, Niebur GL, McNamara LM (2015) Primary cilia exist in a small fraction of cells in trabecular bone and marrow. Calcif Tissue Int 96: 65-72.

Darling EM, Hu JC, Athanasiou KA (2004) Zonal and topographical differences in articular cartilage gene expression. J Orthop Res 22: 1182-1187.

David V, Guignandon A, Martin A, Malaval L, LafageProust MH, Rattner A, Mann V, Noble B, Jones DB, Vico L (2008) Ex vivo bone formation in bovine trabecular bone cultured in a dynamic 3D bioreactor is enhanced by compressive mechanical strain. Tissue Eng Part A 14: 117-126.

Delaine-Smith RM, Sittichokechaiwut A, Reilly GC (2014) Primary cilia respond to fluid shear stress and mediate flow-induced calcium deposition in osteoblasts. FASEB J 28: 430-439.

Freeman FE, Haugh MG, McNamara LM (2015) An in vitro bone tissue regeneration strategy combining chondrogenic and vascular priming enhances the mineralization potential of mesenchymal stem cells in vitro while also allowing for vessel formation. Tissue Eng Part A 21: 1320-1332.

Gardner K, Arnoczky SP, Lavagnino M (2011) Effect of in vitro stress-deprivation and cyclic loading on the length of tendon cell cilia in situ. J Orthop Res 29: 582-587.

Garman R, Gaudette G, Donahue LR, Rubin C, Judex $\mathrm{S}$ (2007) Low-level accelerations applied in the absence 
of weight bearing can enhance trabecular bone formation. J Orthop Res 25: 732-740.

Gerdes JM, Davis EE, Katsanis N (2009) The vertebrate primary cilium in development, homeostasis, and disease. Cell 137: 32-45.

Gurkan UA, Krueger A, Akkus O (2011) Ossifying bone marrow explant culture as a three-dimensional mechanoresponsive in vitro model of osteogenesis. Tissue Eng Part A 17:417-428.

Hoey DA, Chen JC, Jacobs CR (2012a) The primary cilium as a novel extracellular sensor in bone. Front Endocrinol 3: 75.

Hoey DA, Kelly DJ, Jacobs CR (2011) A role for the primary cilium in paracrine signaling between mechanically stimulated osteocytes and mesenchymal stem cells. Biochem Biophys Res Commun 412: 182-187.

Hoey DA, Tormey S, Ramcharan S, O’Brien FJ, Jacobs CR (2012b) Primary cilia-mediated mechanotransduction in human mesenchymal stem cells. Stem Cells 30: 25612570 .

Huber C, Cormier-Daire V (2012) Ciliary disorder of the skeleton. Am J Med Genet C Semin Med Genet 160C: 165-174.

Judex S, Lei X, Han D, Rubin C (2007) Low-magnitude mechanical signals that stimulate bone formation in the ovariectomized rat are dependent on the applied frequency but not on the strain magnitude. J Biomech 40: 1333-1339.

Justesen J, Stenderup K, Ebbesen EN, Mosekilde L, Steiniche T, Kassem M (2001) Adipocyte tissue volume in bone marrow is increased with aging and in patients with osteoporosis. Biogerontology 2: 165-171.

Knothe Tate ML (2003) "Whither flows the fluid in bone?" An osteocyte's perspective. J Biomech 36: 14091424.

Kobayashi T, Dynlacht BD (2011) Regulating the transition from centriole to basal body. J Cell Biol 193: 435-444.

Lee GM, Diguiseppi J, Gawdi GM, Herman B (1987) Chloral hydrate disrupts mitosis by increasing intracellular free calcium. J Cell Sci 88: 603-612.

Lindner U, Kramer J, Behrends J, Driller B, Wendler NO, Boehrnsen F, Rohwedel J, Schlenke P (2010) Improved proliferation and differentiation capacity of human mesenchymal stromal cells cultured with basementmembrane extracellular matrix proteins. Cytotherapy 12: 992-1005.

Litzenberger JB, Kim JB, Tummala P, Jacobs CR (2010) Beta1 integrins mediate mechanosensitive signaling pathways in osteocytes. Calcif Tissue Int 86: 325-332.

Luu YK, Capilla E, Rosen CJ, Gilsanz V, Pessin JE, Judex S, Rubin CT (2009) Mechanical stimulation of mesenchymal stem cell proliferation and differentiation promotes osteogenesis while preventing dietary-induced obesity. J Bone Miner Res 24: 50-61.

Malone AM, Anderson CT, Tummala P, Kwon RY, Johnston TR, Stearns T, Jacobs CR (2007) Primary cilia mediate mechanosensing in bone cells by a calciumindependent mechanism. Proc Natl Acad Sci USA 104: 13325-13330.
Marie PJ, Hay E (2013) Cadherins and Wnt signalling: a functional link controlling bone formation. Bonekey Rep 2: 330 .

Nguyen AM, Jacobs CR (2013) Emerging role of primary cilia as mechanosensors in osteocytes. Bone 54: 196-204.

Novarino G, Akizu N, Gleeson JG (2011) Modeling human disease in humans: the ciliopathies. Cell 147: 70-79.

Parfitt AM, Drezner MK, Glorieux FH, Kanis JA, Malluche H, Meunier PJ, Ott SM, Recker RR (1987) Bone histomorphometry: standardization of nomenclature, symbols, and units. Report of the ASBMR Histomorphometry Nomenclature Committee. J Bone Miner Res 2: 595-610.

Piekarski K, Munro M (1977) Transport mechanism operating between blood supply and osteocytes in long bones. Nature 269: 80-82.

Pittenger MF, Mackay AM, Beck SC, Jaiswal RK, Douglas R, Mosca JD, Moorman MA, Simonetti DW, Craig S, Marshak DR (1999) Multilineage potential of adult human mesenchymal stem cells. Science 284: 143-147.

Praetorius HA, Spring KR (2002) Removal of hte MDCK cell primary cilium abolishes flow sensing. J Membr Biol 191:69-76.

Rubin C, Turner AS, Muller R, Mittra E, McLeod K, Lin W, Qin YX (2002) Quantity and quality of trabecular bone in the femur are enhanced by a strongly anabolic, noninvasive mechanical intervention. J Bone Miner Res 17: 349-357.

Rubin C, Xu G, Judex S (2001) The anabolic activity of bone tissue, suppressed by disuse, is normalized by brief exposure to extremely low-magnitude mechanical stimuli. FASEB J 15: 2225-2229.

Rubin CT, Capilla E, Luu YK, Busa B, Crawford H, Nolan DJ, Mittal V, Rosen CJ, Pessin JE, Judex S (2007) Adipogenesis is inhibited by brief, daily exposure to highfrequency, extremely low-magnitude mechanical signals. Proc Natl Acad Sci USA 104: 17879-17884.

Schneider L, Clement CA, Teilmann SC, Pazour GJ, Hoffmann EK, Satir P, Christensen ST (2005) PDGFRalphaalpha signaling is regulated through the primary cilium in fibroblasts. Curr Biol 15: 1861-1866.

Sims NA, Walsh NC (2012) Intercellular cross-talk among bone cells: new factors and pathways. Curr Osteoporos Rep 10: 109-117.

Sorokin S (1962) Centrioles and the formation of rudimentary cilia by fibroblasts and smooth muscle cells. J Cell Biol 15: 363-377.

Soves CP, Miller JD, Begun DL, Taichman RS, Hankenson KD, Goldstein SA (2014) Megakaryocytes are mechanically responsive and influence osteoblast proliferation and differentiation. Bone 66: 111-120.

Temiyasathit S, Tang WJ, Leucht P, Anderson CT, Monica SD, Castillo AB, Helms JA, Stearns T, Jacobs CR (2012) Mechanosensing by the primary cilium: deletion of Kif3A reduces bone formation due to loading. PLoS One 7: e33368.

Tummala P, Arnsdorf EJ, Jacobs CR (2010) The role of primary cilia in mesenchymal stem cell differentiation: 
a pivotal switch in guiding lineage commitment. Cell Mol Bioeng 3: 207-212.

Uzbekov RE, Maurel DB, Aveline PC, Pallu S, Benhamou CL, Rochefort GY (2012) Centrosome fine ultrastructure of the osteocyte mechanosensitive primary cilium. Microsc Microanal 18: 1430-1441.

Verbruggen SW, Vaughan TJ, McNamara LM (2014) Fluid flow in the osteocyte mechanical environment: a fluid-structure interaction approach. Biomech Model Mechanobiol 13: 85-97.

Vivanco J, Garcia S, Ploeg HL, Alvarez G, Cullen D, Smith EL (2013) Apparent elastic modulus of ex vivo trabecular bovine bone increases with dynamic loading. Proc Inst Mech Eng H 227: 904-912.

Weinbaum S, Cowin SC, Zeng Y (1994) A model for the excitation of osteocytes by mechanical loading-induced bone fluid shear stresses. J Biomech 27:339-360.

Wheatley DN, Wang AM, Strugnell GE (1996) Expression of primary cilia in mammalian cells. Cell Biol Int 20: 73-81.

Xu L, Meng F, Ni M, Lee Y, Li G (2013) N-cadherin regulates osteogenesis and migration of bone marrowderived mesenchymal stem cells. Mol Biol Rep 40: 2533 2539.

Young YN, Downs M, Jacobs CR (2012) Dynamics of the primary cilium in shear flow. Biophys J 103: 629-639.

\section{Discussion with Reviewer}

Reviewer I: What are the clinical implications of alterations to cilia as they apply to bone and marrow health? Authors: Primary cilia play an important role in development and maintaining homeostasis. Alterations in cilia can lead to ciliopathies that affect numerous tissues including bone, kidney, brain, retina and liver. The presence of cilia in bone marrow and their modulation after mechanical stimulation indicates that the mechanical signal from LMMS is sensed in the marrow, and, like tenocytes, the cells respond by retracting their cilia. Further studies are warranted to identify the function of primary cilia in bone marrow, which may lead to new targets for therapeutics.

Reviewer I: Why were there too few colonies in the chloral hydrate $(\mathrm{CH})$ groups to determine proliferation? Did the authors take steps to explain the lack of colony formation? How does direct stimulation of MSCs translate to a clinical setting?

Authors: The reviewer raises a very interesting question. First, we note that these cells were isolated seven days after the last $\mathrm{CH}$ treatment, and, according to previous studies, the cells would have recovered from the $\mathrm{CH}$ mediated cilia disruption. However, we suspect that there may be residual effects of the $\mathrm{CH}$ treatment. In this case, the lack of colony formation may reflect the disruption of the cilia in the treated groups. A previous study saw that deletion of cilia by siRNA prevented cells from attaching to the tissue culture plastic. As such, our findings may not reflect an actual decrease in fibroblast like cell population, but instead an inability of these cells to attach. The other reviewer commented that $\mathrm{CH}$ affects the cytoskeleton, and this can affect the ability of cells to enter G1, which may also contribute this finding.

Reviewer II: Cilia incidence in vitro: The authors have cultured MCSs in the presence of serum. Most studies also include cultures where cells have been serum-starved as this induces greater cilia numbers as cells enter G0. If cells are removed from tissue and cultured in serum (as in this study), then it is not surprising that cilia incidence was low given cells will be stimulated to proliferate. MSCs usually reside in a hypoxic niche within the bone marrow and have low self-renewal rates. The authors do not seem to have considered this or previous publications describing many cultures condition as that may influence ciliation.

Authors: We agree with the reviewer on this point. Dividing MSCs may only express a cilium briefly as they progress through the cell cycle and serum starving the cells would promote cilia expression. Using serum starving may have bolstered the understanding of how effective chloral hydrate $(\mathrm{CH})$ was at cilia knockdown in these cells. However, the existing literature makes clear that $\mathrm{CH}$ at the concentration used here knocks down cilia on cells, including MSCs that are not dividing. This 2D study with serum was performed to complement the $3 \mathrm{D}$ study in the trabecular bone explants, where serum was present and the MSCs are maintained in their niche.

Editor's note: The Scientific Editor responsible for this paper was Chris Evans. 